\title{
Modeling spike timing dependent plasticity with a retrograde transmitter
}

\author{
Bernd Porr*1 and Florentin Woergoetter ${ }^{2}$
}

\author{
Address: ${ }^{1}$ Electronics and Electrical Engineering, Glasgow Universitiy, Glasgow, G12 8LT, UK and ${ }^{2}$ Berstein Center for Computational \\ Neuroscience, University of Göttingen, Goettingen, Germany \\ Email: Bernd Porr* - b.porr@elec.gla.ac.uk \\ * Corresponding author
}

from Eighteenth Annual Computational Neuroscience Meeting: CNS*2009

Berlin, Germany. 18-23 July 2009

Published: I 3 July 2009

BMC Neuroscience 2009, I0(SuppI I):PI94 doi:I0.I |86/I47|-2202-I0-SI-PI94

This abstract is available from: http://www.biomedcentral.com//47I-2202/I0/SI/PI94

(c) 2009 Porr and Woergoetter; licensee BioMed Central Ltd.

\section{Introduction}

Spike timing dependent plasticity (STDP) is a special form of plasticity where the timing of pre- and postsynaptic events determine if the synapse undergoes LTP or LTD. A popular way to model STDP is to use the derivative of the postsynaptic potential or Calcium concentration and correlate this with the NMDA activation [1]. This approach leads automatically to the well-known biphasic STDP curve. Common to all models is that at the end the actual computation is performed postsynaptically for both LTP and LTD.

\section{Using a retrograde transmitter to model STDP In contrast to our previous model [1] we propose that LTD is computed on the pre- and not on the postsynaptic side while LTP is computed on the postsynaptic side [2].}

The computation of LTP is performed in the well-established way by correlating the presynaptic activation (NMDA) with the derivative of the postsynaptic potential (see Figure 1B). We propose that LTD is triggered by a retrograde transmitter (cannabinoids or glutamate), which is released from the postsynaptic membrane and diffuses to the presynaptic terminal where it causes LTD if it coincides with presynaptic NMDA activation (Figure 1C). Consequently, we have to define our learning rule so that it models LTP and LTD separately: $\Delta \rho=\mu u \Theta\left[v^{\prime}\right]-\gamma u \Theta\left[v^{\prime} t-\tau\right]$ where $u$ is the NMDA activation, $v$ the postsynaptic potential, $t$ the time the retrograde transmitter needs to diffuse from the post- to the presynaptic terminal and $Q$ is the heaviside function?. This rule can be understood in the following way. The positive part of the derivative can be interpreted as Ca influx into the postsynaptic neuron that is then correlated with the NMDA channel activation. However, the negative part of the derivative of the postsynaptic potential has no biophysical meaning in terms of LTD. Instead we model LTD as a retrograde transmission of a transmitter that travels from the postsynaptic membrane to the presynaptic terminal. The crucial point here is that this retrograde transmitter needs time to diffuse to the presynaptic terminal that is represented by the shift $t$. Because of this delay LTP and LTD do not cancel out and we obtain the bi-phasic STDP curve (Figure 1D).

\section{Conclusion}

We have successfully modeled STDP with the help of a retrograde transmitter responsible for the LTD part of STDP. This reflects very recent experimental results [2] that LTD seems to be a presynaptic process while LTP seems to be postsynaptic process.

\section{References}

I. Saudargiene A, Porr B, Wörgötter F: Local learning rules: Predicted influence of dendritic location on synaptic modification in spike timing dependent plasticity. Biol Cybern 2004, 92:128-138.

2. Moreno $R$, Paulsen $O$ : Spike timing-dependent long term depression in the CAI region of the hippocampus. FENS 2008 , 4: $\quad$ [http://fens2008.neurosciences.asso.fr/abstracts/R7/ 
A

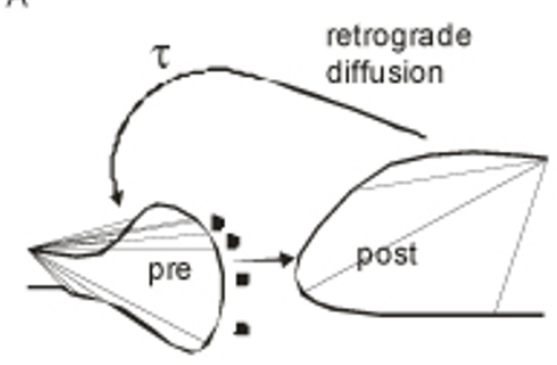

B

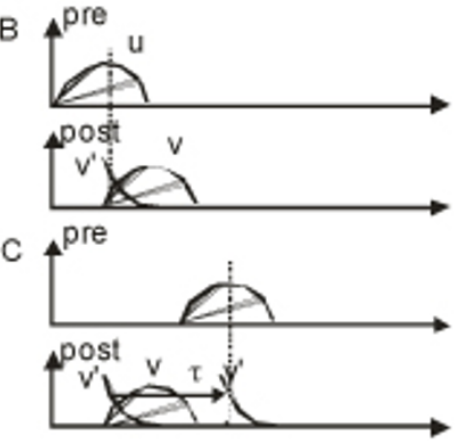

D

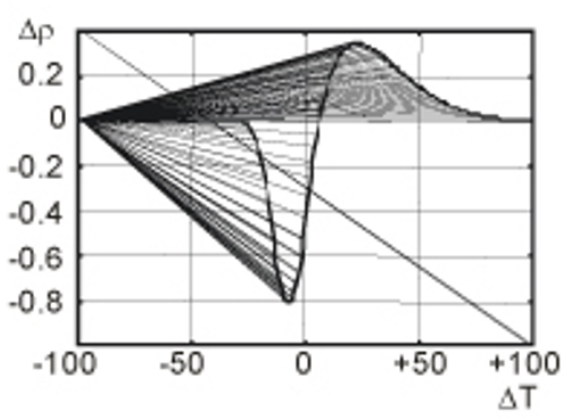

Figure I

A) Synapse, B) LTP induction, C) LTD induction, D) resulting STDP curve.

Publish with Bio Med Central and every scientist can read your work free of charge

"BioMed Central will be the most significant development for disseminating the results of biomedical research in our lifetime. "

Sir Paul Nurse, Cancer Research UK

Your research papers will be:

- available free of charge to the entire biomedical community

- peer reviewed and published immediately upon acceptance

- cited in PubMed and archived on PubMed Central

- yours - you keep the copyright 